\title{
Construyendo el Pacto Mundial para la Migración: la seguridad humana como paradigma diplomático
}

\author{
Fernando De la Mora Salcedo*
}

\begin{abstract}
RESUMEN
El Pacto Mundial para la Migración Segura, Ordenada y Regular (PMM) es un logro diplomático destacado para las Naciones Unidas. El proceso diplomático que dio pie al PMM fue diseñado con la seguridad humana en mente y con el objetivo de atender a la migración en todas sus dimensiones. Las negociaciones mostraron una tensión entre preocupaciones sobre la soberanía estatal y los derechos de las personas migrantes. Si bien, existen críticas validas sobre el PMM, el empleo de la seguridad humana como paradigma diplomático permitió diálogos incluyentes de los cuales resultó un marco cooperativo para fortalecer las capacidades de los estados ante el fenómeno migratorio. Tener al ser humano en el centro del análisis se dice fácil, pero traducirlo en políticas públicas negociadas entre gobiernos conlleva serios retos. En temas tan variados como detención de menores, protección laboral y debido proceso, el PMM representa una contribución de la seguridad humana a la migración en el presente y un modelo a considerar para futuros procesos diplomáticos.
\end{abstract}

\section{Palabras Clave}

Migración; diplomacia; seguridad humana; Naciones Unidas; desarrollo internacional..

\section{Title}

Building the Global Compact for Migration: human security as a diplomatic paradigm

\section{Abstract}

The Global Compact for Safe, Orderly and Regular Migration (GCM) is a notable diplomatic achievement for the United Nations. The diplomatic process that led to the GCM was designed with human security in mind and with the objective to address migration in all its dimensions. Negotiations demonstrated a tension between concerns over state sovereignty and the rights of migrants. While valid criticism exists surrounding the GCM, employing human security as a diplomatic paradigm gave way to inclusive dialogues, resulting in a cooperative framework to strengthen States' capacities to address the migratory phenomenon. Having the human being at the center of the analysis is easy said, but translating it into intergovernmentally negotiated public policies carried significant challenges. On such varied topics like child detention, labor protection and due process, the GCM represents a contribution from human security to present day migration, and provides a model to be considered for future diplomatic processes.

\section{KEYWORDS}

Migration; diplomacy; human security; United Nations; international development.

\section{DOI:}

https://doi.org// 0.15366/relacionesinternacionales2020.43.005

Formato de citación recomendado:

DE LA MORA SALCEDO, Fernando, "Construyendo el Pacto Mundial para la Migración: la seguridad humana como paradigma diplomático ”, en Relaciones Internacionales, n 43, 2020, pp. 87 - I 10.
* Fernando

DE LA MORA

SALCEDO,

Diplomático de carrera del Servicio Exterior Mexicano. Actualmente funge como Coordinador de Asuntos

Económicos,

Sociales y de Migración en la Misión Permanente de México ante las Naciones Unidas.

En la Cancillería,

fue Director de

Coordinación Interinstitucional del Instituto Matías Romero, la academia diplomática de México. Es licenciado en Relaciones Internacionales por la University of British Columbia y Maestro en Derecho por la Universidad de Nuevo México. Es asociado del Consejo Mexicano de Asuntos Internacionales (COMEXI).

Recibido:

01/10/2019

Aceptado:

19/12/2019 


\section{$\mathrm{I}$}

\section{ntroducción}

El diez de diciembre de 2018, líderes mundiales se dieron cita en Marrakech, Marruecos, para adoptar el Pacto Mundial para la Migración Segura, Ordenada y Regular (PMM). La Cumbre de Marrakech fue la culminación de décadas de esfuerzos diplomáticos que resultó en el primer documento negociado bajo los auspicios de las Naciones Unidas (ONU) que atendería todas las dimensiones de la migración internacional. La migración es un fenómeno profundamente humano que afecta tanto a los individuos que emigran como a las comunidades en contextos que origen, tránsito, destino y retorno. El PMM no solo constituye un acuerdo integral pionero en materia migratoria, sino que es también el primer "Pacto Mundial”, una designación sin precedentes para un instrumento diplomático.

El hecho de que un acuerdo de esta naturaleza se haya alcanzado en momentos caracterizados por un discurso político de creciente xenofobia, nacionalismos excluyentes y el ascenso populismos merece un análisis cuidadoso. Muchas de las narrativas en torno a la migración tienden a materializar dicotomías de "otredad”, prestándose fácilmente procesos de securitización que privilegian al estado como sujeto primario'. No obstante, el PMM es reconocido como un instrumento que no solamente tiene el potencial de fortalecer la protección a los derechos humanos, sino como herramienta para robustecer las capacidades soberanas de los estados para gestionar la migración efectivamente.

Este artículo explora el papel de la seguridad humana como paradigma diplomático que logró conciliar visiones aparentemente yuxtapuestas sobre la migración internacional, resultando en un entendimiento común entre Estados Miembros. Resalta sus contribuciones y desafíos en términos prácticos, para posteriormente exponer paralelismos que podrían ser aplicados a otros procesos de negociación. Está elaborado desde la perspectiva de un practicante de la diplomacia multilateral, de tal suerte que puede complementar múltiples marcos teóricos. Mediante la revisión de pronunciamientos y documentos oficiales de las negociaciones, las coberturas mediáticas y las aportaciones de la academia y la sociedad civil, el artículo demuestra que la seguridad humana, aplicada como paradigma mediante técnicas negociadoras, tiene el potencial facilitar entendimientos sobre temas complejos.

El artículo está dividido en cinco secciones: las dos primeras proporcionan antecedentes sobre la evolución de las discusiones en materia migratoria y de seguridad humana en la ONU, respectivamente. La tercera sección bosqueja el diseño del proceso de negociación diplomática. La cuarta analiza algunos de los veintitrés objetivos del PMM desde la perspectiva de seguridad humana, identificando áreas que fueron debatidas durante el proceso negociador. El documento concluye con reflexiones sobre los retos y oportunidades para negociaciones multilaterales basadas en la seguridad humana a futuro.

\section{Migración y la ONU}

Durante muchos años, los diplomáticos se rehusaron a discutir cuestiones sobre migración

PINYOL-JIMENEZ, Gemma "Otro paradigma migratorio: La percepción del fenómeno como una amenaza ha privado de un debate que es necesario" en El País, 6 de julio de 2018: https://elpais.com/elpais/20 I8/07/05/opinion/I5308I4645_466534.html [Consultado 5 de diciembre de 2019]. 
internacional en la ONU. Era visto como un tema complejo, con carga emocional, que tocaba áreas de soberanía y seguridad nacionales ${ }^{2}$. Los esfuerzos para dialogar sobre la materia se remontan a la Conferencia Internacional sobre Población y Desarrollo de 1984, seguida por la Convención Internacional para la Protección de los Derechos de los Trabajadores Migrantes y sus Familiares de 1990 y el primer Diálogo de Alto Nivel sobre Migración y Desarrollo, celebrado en 2006. Estas iniciativas intentaron avanzar discusiones sobre migración internacional, pero no lograron hacerlo desde una perspectiva integral. También se presentaron resoluciones concomitantes en la Asamblea General y el Consejo de Derechos Humanos; de valor limitado ante las resistencias incansables a dialogar sobre el tema a nivel multilateral ${ }^{3}$. Los estados tendían a aproximarse a la migración ya sea desde una perspectiva de derechos humanos, desarrollo económico o gestión. Consecuentemente, no existía un marco acordado para la gobernanza integral de la migración ${ }^{4}$.

Un hito importante fue la adopción de la Agenda 2030 para el Desarrollo Sostenible en 2015. Por primera vez, el fenómeno migratorio era reconocido de manera holística:

"Reconocemos la positiva contribución de los migrantes al crecimiento inclusivo y al desarrollo sostenible. Reconocemos también que la migración internacional es una realidad pluridimensional de gran pertinencia para el desarrollo de los países de origen, tránsito y destino que exige respuestas coherentes e integrales. Cooperaremos en el plano internacional para garantizar la seguridad, el orden y la regularidad de las migraciones, respetando plenamente los derechos humanos y dispensando un trato humanitario a los migrantes, sea cual sea su estatus migratorio, y a los refugiados y los desplazados. Esa cooperación también deberá fortalecer la resiliencia de las comunidades que acogen a los refugiados, particularmente en los países en desarrollo. Subrayamos que los migrantes tienen derecho a regresar a su país de nacionalidad y recordamos que los Estados deben velar por que se reciba adecuadamente a los nacionales que regresen a su país." 5 .

Concretamente, la Agenda 2030 establece en su meta 10.7 "Facilitar la migración y la movilidad ordenadas, seguras, regulares y responsables de las personas, incluso mediante la aplicación de políticas migratorias planificadas y bien gestionadas" ${ }^{6}$. A lo largo de la Agenda, un enfoque centrado en las personas es claramente evidente ${ }^{7}$. La referencia explícita a derechos humanos y trato digno para personas migrantes, independientemente de su condición migratoria, es también un gran logro tratándose de un texto sobre desarrollo ${ }^{8}$. El reconocimiento de que, en su esencia, la migración es un fenómeno humano representa un paso importante en el contexto

2 DE LA MORA SALCEDO, Fernando y GÓMEZ CAMACHO, Juan José, “Negociación de 360 grados: el Pacto Mundial para la Migración Segura, Ordenada y Regular" en Otros Diálogos, n 7, 28 de marzo de 2019.

3 GÓMEZ CAMACHO, Juan José, “Multilateralismo práctico" en Foreign Affairs Latinoamérica, vol. 19, n I, Enero -Marzo 2019, p.76.

4 ÜNVER, Can, “Migration in International Relations: Towards a Rights-Based Approach with Global Compact?" en Perceptions, vol. 22, $n^{\circ} 4$, 2017.

5 ASAMBLEA GENERAL DE LAS NACIONES UNIDAS, A/RES/70// Transformar nuestro mundo: la Agenda 2030 para el Desarrollo Sostenible, Párrafo 29 Nueva York, 21 de octubre de 2015

6 Ibídem, Meta 10.7.

7 PIPER, Nicola, "Migration and the SDGs" en Global Social Policy, vol. 17, n 2, 20I7, pp. $232-233$.

8 ARROCHA, Pablo, DE LA MORA, Fernando y DE LA FUENTE, Juan Ramón “Migración: la perspectiva multilateral” en El Universal, 28 de julio de 2019: https://www.eluniversal.com.mx/nacion/sociedad/migracion-la-perspectiva-multilateral [Consultado 29 de julio de 2019]. 
de la ONU. Su relevancia directa para el enfoque de la seguridad humana es obvio y amplio. A grandes rasgos, los Objetivos de Desarrollo Sostenible representan "un paso significativo para la futura estrategia consistente en mejorar la situación de los migrantes creando indicadores propicios sobre trabajo decente, reducción de la pobreza, mejoras en salud y educación, seguridad alimentaria, vivienda con acceso a agua y saneamiento y protección social adecuadas" 9 .

Mientras que el compromiso de hacer que la migración sea (I) segura, (2) ordenada y (3) regular es políticamente poderoso, hacerlo operativo y simultáneamente mantener un enfoque sobre el individuo representaba un reto. En buena medida, ello se debe a los distintos entendimientos posibles en torno a estas tres palabras importantes. Como muchas acciones en la ONU, fueron necesarias tragedias de alto perfil para que los Estados Miembros comenzaran a acordar lo que realmente significarían estas palabras. Las miles de muertes en el Mar Mediterráneo y el gran flujo de refugiados y migrantes - cuyas muertes se acumulaban - generaron las precondiciones necesarias para entablar conversaciones diplomáticas ${ }^{10}$. Bajo el liderazgo del Presidente del $70^{\circ}$ Periodo de Sesiones de la Asamblea General, se convocó una reunión de alto nivel para atender grandes movimientos de refugiados y migrantes.

Originalmente, la intención era atender únicamente aquellos que requerían "protección internacional" conforme al derecho internacional de refugiados. En términos prácticos, aquellas personas en situación de vulnerabilidad, pero que no caían dentro de la definición legal de refugiado, no estarían cubiertas. Semejante decisión política equivaldría a negligencia hacia una mayoría de personas fuera de sus países de origen, por no hablar de las realidades en el terreno. Las negociaciones de cara a la cumbre produjeron la Declaración de Nueva York sobre Refugiados y Migrantes (DNY)". Esta declaración política, adoptada a nivel de Jefes de Estado y de Gobierno, "lanzó un mensaje directo sobre el papel líder de la migración en las agendas políticas y reconoció la necesidad de un enfoque internacional integral y coordinado"'2. Algunos analistas esperanzados con sus contenidos han señalado que, ostensiblemente, únicamente se logró gracias a la disposición momentánea de los gobiernos a permitir la participación de la ONU en el tema ${ }^{13}$.

La DNY contiene tres series de compromisos: primero, para refugiados; segundo, para migrantes y tercero, para migrantes y refugiados. Incluye además dos anexos: el primero delimita el Marco Integral de Respuestas para Refugiados y establece un proceso de consultas técnicas que resultarían en el Pacto Mundial para Refugiados (PMR), mismas que serían encabezadas por el Alto Comisionado de las Naciones Unidas para los Refugiados (ACNUR). El segundo vislumbra los inicios de un Pacto Mundial para la Migración Segura, Ordenada y Regular, que sería negociado por gobiernos en un proceso encabezado por estados y adoptado en una conferencia intergubernamental. Ergo, la DNY es fundamental en el marco de los esfuerzos para cimentar a la

9 PIPER, Nicola, “Migration and the SDGs”, op. cit., p. 236.

10 DE LA MORA, Fernando y GÓMEZ CAMACHO, Juan José, México ante el Pacto Mundial de Migración, Centro de Investigación y Docencia Económicas (CIDE), Ciudad de México, 2019, p. 7.

" ASAMBLEA GENERAL DE LAS NACIONES UNIDAS, A/RES/7I// Declaración de Nueva York para los Refugiados y los Migrantes, Nueva York, 3 de octubre de 2016

12 SERÓN, Gema, "El Pacto Mundial sobre Migración: algunas reflexiones tras la cumbre en Davos" en Memorando OPEX, $\mathrm{n}^{\circ} 24 \mathrm{I} / 20 \mathrm{I}$, I5 de marzo de 2019: https://www.fundacionalternativas.org/public/storage/opex_documentos_archivos/bbaa6d840e43 I0b6d840 I0b062272d85. pdf, p. 3 [Consultado 10 de junio de 2019].

13 GOTTARDO, Carolina y CYMENT, Paola "The Global Compact for Migration: what could it mean for women and gender relations?" en Gender and Development, vol. 27, $\mathrm{n}^{\circ} \mathrm{I}$, marzo 2019. 
seguridad humana como paradigma guía de la diplomacia migratoria, pues asegura que mientras puedan aplicar marcos jurídicos distintos para personas migrantes, todos deben gozar de la seguridad de persona requerida para trasladarse con seguridad y dignidad. Adicionalmente, la declaración incorporó a la Organización Internacional para las Migraciones (OIM) a la ONU como organización relacionada ${ }^{14}$.

\section{Seguridad Humana y la ONU}

La publicación del Informe sobre Desarrollo Humano del Programa de las Naciones Unidas para el Desarrollo en 1994 fue la entrada oficial del término "seguridad humana" al léxico de la ONU. En él, la seguridad humana está definida como un concepto que "equipara la seguridad con personas en lugar de territorios, con desarrollo en lugar de armamento 15 " y aboga por una perspectiva que contempla desde el individuo hasta lo global como consideraciones relevantes. En su momento, era evidente para practicantes de las relaciones internacionales que un entendimiento de la seguridad internacional basado puramente en el estado sería, en el mejor de los casos, insuficiente para atender las amenazas multidimensionales a la paz. En efecto, la seguridad humana fue uno de los conceptos pioneros que intentó deshacer a aquello que frecuentemente se conocen como "silos" en el sistema ONU, en donde la seguridad, el desarrollo y los derechos humanos están en competencia desarticulada y en rutas de trabajo herméticamente separadas para fines programáticos, presupuestarios y de ejecución. Los conceptos complementarios de "libertad de la necesidad" " "libertad del miedo" proporcionaron un espacio político adecuado para funcionarios tanto en el pilar de seguridad como el de desarrollo.

Si bien, algunos de los primeros opositores a la seguridad humana argumentaron que ésta podría comprometer a la seguridad nacional, sus promotores señalaron que ambos conceptos son complementarios y no deberían entenderse como opuestos. La evolución del derecho internacional de los derechos humanos desde la Segunda Guerra Mundial es un precursor clave en este sentido. No obstante, una preocupación tangible de algunos gobiernos era que este nuevo enfoque sobre la seguridad del individuo podría efectivamente socavar la soberanía nacional. Tras la tragedia de Ruanda en 1994 y los bombardeos "ilegales pero legítimos" 16 de Kosovo en 1999 , estas alarmas no estaban necesariamente fuera de lugar. Al poco tiempo, en 200I, la Comisión Internacional sobre Intervención y Soberanía de los Estados —convocada totalmente por fuera de la ONU - presentó el concepto de "Responsabilidad de Proteger" (R2P) como un esfuerzo para promover discusiones sobre soberanía y derechos humanos en el siglo XXI.A esto le siguió el Documento Resultado de la Cumbre Mundial de 2005, en la que los Estados Miembros se comprometieron a "discutir y definir la noción de Seguridad Humana en la Asamblea General" ${ }^{7}$.

Los Estados Miembros asumieron el liderazgo al definir lo que era - y lo que no era - la seguridad humana adoptando la resolución de la Asamblea General 66/290. En ella se define como

\footnotetext{
14 ORGANIZACIÓN INTERNACIONAL PARA LAS MIGRACIONES, “IOM Becomes a Related Organization to the UN”, IOM Press Release, 25 de julio 2016: https://www.iom.int/news/iom-becomes-related-organization-un [Consultado 10 de junio de 2019].

15 PROGRAMA DE LAS NACIONES UNIDAS PARA EL DESARROLLO, Informe sobre Desarrollo Humano 1994, Naciones Unidas, Nueva York, 1994, p. 3

16 INDEPENDENT INTERNATIONAL COMMISSION ON KOSOVO, The Kosovo Report: Conflict, International Response, Lessons Learned, Oxford University Press, Oxford, 2000, p. 4.

17 ASAMBLEA GENERAL DE LAS NACIONES UNIDAS, A/RES/60/I Documento Final de la Cumbre Mundial 2005, (Párrafo I43) Nueva York, 24 de octubre de 2005
} 
"enfoque que ayuda a los Estados Miembros a determinar y superar las dificultades generalizadas e intersectoriales que afectan a la supervivencia, los medios de subsistencia y la dignidad de sus ciudadanos" ${ }^{18}$. La resolución continúa identificando una serie de entendimientos comunes que efectivamente atienden las preocupaciones de los gobiernos en ese momento. Por ejemplo, el uso de las palabras "sus ciudadanos" en lugar de "poblaciones" o simplemente "personas" acomodó a gobiernos preocupados ante una eventual invocación de la seguridad humana para interferir en prerrogativas soberanas de los estados.

Mientras tanto, los promotores crearon la Red de Seguridad Humana ${ }^{19}$ a fin de coordinar sus posiciones y dotar de mayor prominencia a esta agenda, particularmente tras la colaboración exitosa que dio pie a la Convención de Ottawa sobre la Prohibición del Empleo,Almacenamiento, Producción y Transferencia de Minas Antipersonal y sobre su Destrucción ${ }^{20}$. Gradualmente, la sociedad civil, académicos y los mismos diplomáticos formaban parte de discusiones que integraban perspectivas enfocadas en el bienestar individual a las negociaciones multilaterales. No obstante, la historia de la seguridad humana en la ONU está caracterizada por una persistente, aunque fluida, tensión con la soberanía estatal y sus aproximaciones tradicionales a la seguridad ${ }^{21}$. Independientemente de si el concepto es citado o no explícitamente en círculos diplomáticos, sus contribuciones a los ámbitos de seguridad y desarrollo son ampliamente reconocidos ${ }^{22}$.

Es menester señalar que un paradigma que ha contribuido a discusiones sobre seguridad, desarrollo y derechos humanos en la ONU es de utilidad para atender algunas de las amenazas emergentes. Innovaciones como el Tratado sobre el Comercio de Armas ${ }^{23}$ y el Tratado sobre la Prohibición de las Armas Nucleares ${ }^{24}$, así como la propia Agenda 2030 e iniciativas como Derechos Humanos Primero ${ }^{25}$ constituyen ejemplos de cómo la seguridad humana ha permeado exitosamente a procesos diplomáticos en la era posterior al II-S. Ante críticas a la efectividad de la ONU para atender retos añejos y nuevos, atender a la migración a través del lente de la seguridad humana resulta lógico y apropiado.

\section{Diseñando un proceso diplomático adecuado}

Para entender plenamente el PMM y el papel del paradigma de seguridad humana en su desarrollo, es indispensable analizar el proceso diplomático que llevó al acuerdo: las modalidades con las

18 ASAMBLEA GENERAL DE LAS NACIONES UNIDAS, A/RES/66/290 Seguimiento del párrafo I43, relativo a la seguridad humana, del Documento Final de la Cumbre Mundial 2005, (Párrafo 3) Nueva York, 25 de octubre de 2012.

19 Los miembros son Austria, Canadá, Chile, Costa Rica, Grecia, Irlanda, Jordania, Mali, Noruega, Eslovenia, Suiza, Tailandia y Sudáfrica (como observador).

20 ROCK, Allan, “The Human Security Network, Fifteen Years On” en Center for International Policy Studies, 21 mayo 20I3: https://www.cipscepi.ca/20I3/05/2I/the-human-security-network-fifteen-years-on/ [Consultado 30 de julio de 2019].

21 MACFARLANE, S. Neil y FOON KHONG, Yuen, Human Security and the UN: A Critical History, Indiana University Press, Bloomington, 2006, Pp. $225-234$.

22 MCRAE, Rob, “International Relations and the New Diplomacy" en MCRAE, Rob y HUBERT, Don (eds.), Human Security and the New Diplomacy, McGill-Queen’s University Press, Montreal, 200 I, pp. 250-253.

${ }^{23}$ KYTOMAKI, Elli, The Arms Trade Treaty and Human Security: Cross-cutting Benefits of Accession and Implementation, Chatham House, Londres, 20 I 5: https://www.chathamhouse.org/sites/default/files/field/field_document/20I50220ATTKytomaki.pdf [Consultado 20 de junio de 2019 ].

24 BOLTON, Matthew, The Nuclear Weapons Ban and Human Security for All, Freidrich Ebert Stiftung, Nueva York, 20 I7: http://library.fes.de/pdffiles/iez/I3435.pdf [Consultado 19 de junio de 2019]

25 PROGRAMA DE LAS NACIONES UNIDAS PARA EL DESARROLLO “Putting Human Rights Up Front”, Nueva York, 7 de agosto de 20 I8: https://stories.undp.org/putting-human-rights-up-front [Consultado 19 de junio de 2019]. 
que se estructura la negociación. La literatura académica o política suele prestar poca atención a modalidades, toda vez que los funcionamientos internos de procesos de la ONU tienden a cambiar poco a lo largo del tiempo y no son generalmente espacios propicios para la creatividad. Sin embargo, es ahí en donde comienza a permear la seguridad humana como paradigma en el proceso diplomático.

El Presidente de la Asamblea General nombró a los Representantes Permanentes de México y Suiza como cofacilitadores del proceso, quienes diseñarían y conducirían las negociaciones. En la resolución de modalidades, los cofacilitadores propusieron un proceso de tres fases: consulta, balance y negociación. Mientras que varias delegaciones habrían preferido comenzar negociaciones inmediatamente, es probable que hacerlo hubiese polarizado irremediablemente el ambiente parlamentario de cara a las percepciones equivocadas sobre migración ${ }^{26}$.

La primera fase (consultas) reuniría a estados y a otras partes interesadas a fin de compartir datos, evidencias y realidades. Era necesario un entendimiento profundo y objetivo del fenómeno y los espacios políticos nacionales parecían incapaces de sostener diálogos constructivos ${ }^{27}$. Esta conversación no podría ser únicamente entre Estados Miembros. La sociedad civil y otras partes interesadas, como empleadores, sindicatos y parlamentarios aportarían sus perspectivas para dar forma al $\mathrm{PMM}^{28}$. El mismo criterio aplicaría en el ámbito regional, con la participación de las comisiones económicas regionales de la $\mathrm{ONU}$ en el proceso de consultas ${ }^{29}$, en donde Estados Miembros y partes interesadas podrían dialogar sobre retos y oportunidades. Al tratarse de migración, este enfoque incluyente de múltiples partes interesadas es ampliamente reconocido como benéfico al atender temas complejos precisamente porque vincula las discusiones con las realidades en el terreno ${ }^{30}$.

Con el mandato de "establecer una serie de principios, compromisos y entendimientos entre los Estados Miembros sobre la Migración Internacional y todas sus dimensiones" ${ }^{31}$, se convocaron seis sesiones temáticas informales:

- Los derechos humanos de todos los migrantes, la inclusión social, la cohesión y todas las formas de discriminación, incluidos el racismo, la xenofobia y la intolerancia.

- La migración irregular y por vías regulares, incluido el trabajo decente, la movilidad laboral, el reconocimiento de las aptitudes y cualificaciones y otras medidas pertinentes.

- La cooperación internacional y la gobernanza de la migración en todas sus dimensiones, como en las fronteras, en tránsito, la entrada, el retorno, la readmisión, la integración y la reintegración.

26 GÓMEZ CAMACHO, Juan José, “Multilaterismo práctico”, op. cit., pp. 79-8I

27 DE LA MORA, et. al., "México ante el Pacto Mundial de Migración..., op. cit. p.8.

${ }^{28}$ El estándar contemporáneo de buena práctica para participación de sociedad civil en procesos de Naciones Unidas es sobre la "base de no-objeción", por la cual todas las ONG con estatus Consultivo ante el Consejo Económico y Social de Naciones Unidas están incluidas en el proceso si se registran, y aquellos que no posean estatus consultivo son invitadas a aplicar. Una vez que lo hacen, la lista de aplicaciones es examinada administrativamente y es circulada a Estados Miembros. Cualquier Estado Miembro puede objetar, resultando en la noparticipación de una ONG. Sin embargo, otro Estado Miembro puede solicitar que la motivación de dicha petición sea de conocimiento público.

29 NACIONES UNIDAS, “Consultas Regionales para el Pacto Mundial sobre Migración” 20I7: https://refugeesmigrants.un.org/regionalconsultations, [Consultado 2 agosto 2019]

30 PURKAYASHTA, Bandana, “Migration, migrants and human security” en Current Sociology Monograph, vol. 66, $\mathrm{n}^{\circ} .2,2018$.

31 ASAMBLEA GENERAL DE LAS NACIONES UNIDAS, Declaración de Nueva York para los Refugiados y los Migrantes, op. cit., Anexo II, Párrafo 2. 
- Las contribuciones de los migrantes y las diásporas a todas las dimensiones del desarrollo sostenible, incluidas las remesas y la transferibilidad de las prestaciones ganadas.

- La respuesta a los factores que impulsan la migración, incluidos los efectos adversos del cambio climático, los desastres naturales y las crisis creadas por el ser humano, mediante la protección y la asistencia, el desarrollo sostenible, la erradicación de la pobreza, y la prevención y resolución de conflictos

- El tráfico de migrantes, la trata de personas y las formas contemporáneas de la esclavitud, en particular la identificación, protección y asistencia apropiadas a los migrantes y las víctimas de la trata ${ }^{32}$.

En lugar de negociar los contenidos del PMM en cada sesión, los cofacilitadores elaboraron resúmenes de las discusiones principales, mismas que a vez eran alimentadas por panelistas expertos ajenos a gobiernos.

Tras haber acumulado grandes cantidades de datos y evidencias sobre una base temática en la fase de consultas, le correspondió a la segunda fase (balance) incorporar explícitamente la perspectiva de seguridad humana a la conversación diplomática. En una reunión en PuertoVallarta, México, en diciembre de 2018, las delegaciones participaron en "grupos de acción". Para evitar reiteración de prioridades temáticas, estos grupos se concentraron en los siguientes niveles de análisis:

- Humano

- Comunitario

- Local/sub nacional

- Nacional

- Regional

- Global $^{33}$

Los diplomáticos participando en estas sesiones analizaron los impactos de sus posiciones nacionales en torno a los ambientes prescritos a cada nivel. Es decir, no habría posición nacional que no tuviera en cuenta su impacto en el individuo. El resultado sería un resumen de los cofacilitadores que constituiría la base para la tercera fase: negociación.

La fase de negociaciones se asemejó más a procesos tradicionales de la ONU, con borradores que recibían comentarios orales y por escrito. En lugar de abrir por completo el ejercicio de redacción, los cofacilitadores escucharon cuidadosamente los comentarios de las delegaciones $y$ otras partes interesadas y reflejaron cambios en iteraciones subsecuentes ${ }^{34}$. Tres elementos fueron esgrimidos de las fases previas. Primero, los Estados Miembros querían un documento que no fuera jurídicamente vinculante ni pesado, pero sí accionable. Segundo, había un reconocimiento que ya existían obligaciones legales internacionales, pero que buena parte del problema para su instrumentación obedecía a la naturaleza dispersa de sus fuentes. Ergo, los

\footnotetext{
32 ASAMBLEA GENERAL DE LAS NACIONES UNIDAS, A/RES/7 I/280 Modalidades para las negociaciones intergubernamentales del pacto mundial para una migración segura, ordenada y regular, Nueva York, 17 abril 2017.

${ }^{33}$ NACIONES UNIDAS “Agenda of the Preparatory (stocktaking) meeting of the Intergovernmental Conference to adopt a Global Compact for Safe, Orderly and Regular Migration", 4 de diciembre de 2017: https://refugeesmigrants.un.org/sites/default/files/pv_agenda_03I 22017 _ rev.pdf, [Consultado 14 de junio de 2019].

${ }^{34}$ DE LA MORA, et. al., "Negociación de 360 grados..." op. cit.
} 
gobiernos no tenían apetito por asumir nuevas obligaciones, pero estarían dispuestos a englobar las existentes en un texto práctico. Tercero y último, se llegó a un entendimiento en torno a la dimensión humana de la discusión. Mientras que el migrante tendría que estar al centro del PMM, también tendrían que estarlo las comunidades de origen, tránsito y destino, con el estado como actor primario (aunque no el único) a cargo de implementar los compromisos del PMM.

Esta sección detalla un proceso de negociación que buscó involucrar tanto a gobiernos como a múltiples partes interesadas en discusiones constructivas sobre migración internacional sobre la base de evidencia en lugar de percepciones. Cualquier impresión que la dignidad o derechos humanos estaban de alguna forma opuestas a las capacidades soberanas de los estados tendría que ser disipada mediante el diálogo abierto. Los Estados Miembros tenían que sentir que sus preocupaciones estaban atendidas, registrando progreso hacia un acuerdo a lo largo de las tres fases del proceso ${ }^{35}$. Simultáneamente, los participantes de la sociedad civil también tendrían que compartir pertenencia del PMM y su proceso, lo cual hicieron promoviendo un enfoque basado en derechos humanos, en cooperación con sindicatos y organizaciones pro migrantes ${ }^{36}$.

\section{Seguridad Humana en el PMM}

Diez principios rectores forman la base del PMM: Centrarse en las personas, cooperación internacional, soberanía nacional, estado de derecho y garantías procesales, desarrollo sostenible, derechos humanos, perspectiva de género, perspectiva infantil, enfoque pan gubernamental y enfoque pan social ${ }^{37}$. El hecho de que "centrarse en las personas" sea el primero de estos principios rectores y que éste sea separado del de los derechos humanos es un indicio claro del enfoque de seguridad humana empleado en el proceso. Adicionalmente, los principios de perspectiva de género e infantiles resaltan la necesidad de atender las vulnerabilidades específicas de ciertos subgrupos de migrantes. La abogacía a favor de los niños y aquellos desplazados por violencia ha sido una característica de larga data en la diplomacia de seguridad humana ${ }^{38}$. Finalmente, el enfoque pansocial representa una expansión del principio centrado en personas, cuya intención es involucrar a las comunidades. Puede atribuirse a antecedentes de proyectos del Fondo Fiduciario de Seguridad Humana ${ }^{39}$.

El PMM incluye veintitrés objetivos específicos. Explicado claramente en el propio PMM, "Cada objetivo contiene un compromiso, seguido de una serie de acciones consideradas pertinentes como instrumentos normativos y mejores prácticas. Con el fin de cumplir los 23 objetivos, recurriremos a esas acciones para lograr la migración segura, ordenada y regular a lo largo de todo el ciclo migratorio" 40

\footnotetext{
35 Ibídem.

36 PIPER, Nicole, “Democratising Migration from the Bottom Up:The Rise of the Global Migrant Rights Movement” en Globalizations, vol. I2, N. 5 , de marzo 2015

37 ASAMBLEA GENERAL DE LAS NACIONES UNIDAS, A/RES/73//95 Pacto Mundial para la Migración Segura, Ordenada y Regular, op.cit.

38 MACFARLANE, et. al., Human Security and the UN... op. cit. pp.2I5-224.

39 FONDO FIDUCIARIO DE LAS NACIONES UNIDAS PARA LA SEGURIDAD HUMANA, "Supporting the strengthening of Government institutions and civil society capacities to improve the protection of vulnerable migrants in transit", 20I5: https://www.un.org/humansecurity/ wp-content/uploads/2017/08/Revised-Mexico-092-Final-Template.pdf [Consultado 2 de agosto de 2019].

40 ASAMBLEA GENERAL DE LAS NACIONES UNIDAS, A/RES/73//95 Pacto Mundial para la Migración Segura, Ordenada y Regular, op. cit., Párrafo 16.
} 
Un repaso superficial de los objetivos del PMM debe ser leído a la luz del proceso diplomático que produjo acuerdo sobre este lenguaje particular, tal y como se describe líneas arriba. Los objetivos todos pueden ser concebidos mediante impactos en el terreno para migrantes individuales y sus comunidades. Las acciones adicionales de las que los Estados pueden hacer uso para cumplir con su compromiso son un dibujo de tales impactos.

\section{TABLA I: Objetivos para la migración segura, ordenada y regular}

- Recopilar y utilizar datos exactos y desglosados para formular políticas con base empíri$\mathrm{ca}$

- Minimizar los factores adversos y estructurales que obligan a las personas a abandonar su país de origen

- Proporcionar información exacta y oportuna en todas las etapas de la migración

- Velar por que todos los migrantes tengan pruebas de su identidad jurídica y documentación adecuada

- Aumentar la disponibilidad y flexibilidad de las vías de migración regular

- Facilitar la contratación equitativa y ética y salvaguardar las condiciones que garantizan el trabajo decente

- Abordar y reducir las vulnerabilidades en la migración

- Salvar vidas y emprender iniciativas internacionales coordinadas sobre los migrantes desaparecidos

- Reforzar la respuesta transnacional al tráfico ilícito de migrantes

- Prevenir, combatir y erradicar la trata de personas en el contexto de la migración internacional

- Gestionar las fronteras de manera integrada, segura y coordinada

- Aumentar la certidumbre y previsibilidad de los procedimientos migratorios para la adecuada verificación de antecedentes, evaluación y derivación

- Utilizar la detención de migrantes solo como último recurso y buscar otras alternativas

- Mejorar la protección, asistencia y cooperación consulares a lo largo de todo el ciclo migratorio

- Proporcionar a los migrantes acceso a servicios básicos

- Empoderar a los migrantes y las sociedades para lograr la plena inclusión y la cohesión social

- Eliminar todas las formas de discriminación y promover un discurso público con base empírica para modificar las percepciones de la migración

- Invertir en el desarrollo de aptitudes y facilitar el reconocimiento mutuo de aptitudes, cualificaciones y competencias

- Crear las condiciones necesarias para que los migrantes y las diásporas puedan contribuir plenamente al desarrollo sostenible en todos los países

- Promover transferencias de remesas más rápidas, seguras y económicas y fomentar la inclusión financiera de los migrantes

- Colaborar para facilitar el regreso y la readmisión en condiciones de seguridad y dignidad, así como la reintegración sostenible

- Establecer mecanismos para la portabilidad de la seguridad social y las prestaciones adquiridas

- Fortalecer la cooperación internacional y las alianzas mundiales para la migración segura, ordenada y regular 
Al iniciar el análisis de la seguridad humana en los objetivos del PMM, resulta útil comenzar con una discusión sobre fronteras. Sería verdaderamente ingenuo —por no decir un incumplimiento de mandato- hablar sobre migración sin atender demarcaciones jurisdiccionales. Al hacerlo, las fronteras inmediatamente traen consigo interpretaciones tradicionales realistas: líneas estratégicas que deben ser defendidas militarmente a fin de que no sea cuestionada la soberanía misma del estado ${ }^{41}$. Si bien no puede existir mayor disputa sobre el hecho de que una frontera es el inicio y fin de la jurisdicción nacional, las conversaciones diplomáticas al respecto brillaban por su ausencia. Lo anterior, pese a la aseveración obvia de que la gestión fronteriza efectiva requeriría mejor cooperación con la jurisdicción del otro lado, así como los arreglos institucionales correspondientes ${ }^{42}$. En lugar de entrar en interpretaciones postmodernas de barreras, fronteras y realidades socioculturales relacionadas con el concepto ${ }^{43}$, el PMM adopta un enfoque que respeta los entendimientos tradicionales, pero mejora los compromisos políticos en torno al tema. En su Objetivo II, el PMM dice "Nos comprometemos a gestionar nuestras fronteras nacionales de manera coordinada, promoviendo la cooperación bilateral y regional, garantizando la seguridad de los estados, las comunidades y los migrantes, y facilitando la circulación transfronteriza de personas de manera segura y regular, evitando al mismo tiempo la migración irregular. Nos comprometemos además a aplicar políticas de gestión de las fronteras que respeten la soberanía nacional, el estado de derecho, las obligaciones en virtud del derecho internacional y los derechos humanos de todos los migrantes, independientemente de su estatus migratorio, que no sean discriminatorias y que tengan en cuenta la perspectiva de género e infantil” ${ }^{44}$.

El balance entre las preocupaciones sobre control fronterizo por parte de algunos gobiernos, aunado con la manifestación de que las fronteras mal gestionadas podrían contribuir a la migración insegura y desordenada está asentado en el PMM. Algunas críticas en esta materia son que el acuerdo cae por debajo de los "Principios y Directrices Recomendados sobre los Derechos Humanos en las Fronteras Internacionales" de la Oficina del Alto Comisionado de la ONU sobre Derechos Humanos. Sin embargo, ello se debe precisamente a que el Pacto "hace énfasis en categorías particulares de migrantes en lugar de prácticas y políticas de los estados que generan tales vulnerabilidades, como pueden ser controles fronterizos y políticas restrictivas de admisión" ${ }^{45}$.

El compromiso citado arriba sobre gestión integrada de frontera ejemplifica algunas de las técnicas lingüísticas empleadas en el PMM. En lugar de imponer un compromiso negativo (por ejemplo no tener políticas migratorias o fronterizas que afecten a poblaciones vulnerables), se asentó un compromiso positivo. En lugar de vaguedad (por ejemplo en beneficio de todas las personas), la seguridad de estados, comunidades y migrantes es citada explícitamente. Finalmente, condicionantes, como son, "según sea adecuado", o "de conformidad con legislación nacional” no se encuentran en el texto. El grado al que tal flexibilidad está integrada al PMM deriva del trato

\footnotetext{
41 FERREIRA, Susana, Human Security and Migration in Europe's Southern Borders, Palgrave MacMillan, Cham, 20I9, pp. 5 I-53.

42 PECOUD, A y DE GUCHTENEIRE, P, “International Migration, Border Controls and Human Rights: Assessing the Relevance of a Right to Mobility” en Journal of Borderlands Studies, vol. 2I, $\mathrm{n}^{\circ}$. I, 2006.

${ }^{43}$ COLOMÉ MENÉNDEZ, Desirée, “Fronteras movedizas”, en Opiniones Oportunas del Consejo Mexicano de Asuntos Internacionales, 26 julio 20 I 9 http://revistafal.com/fronteras-movedizas/ [Consultado 27 de julio de 2019].

${ }^{44}$ ASAMBLEA GENERAL DE LAS NACIONES UNIDAS, A/RES/73//95 Pacto Mundial para la Migración Segura, Ordenada y Regular (Párrafo 27).

45 GUILD, et. al., From Zero to Hero? ..., op. cit., p. 10.
} 
diferenciado de los objetivos vis-a-vis sus acciones a las que los estados "recurrirán" ${ }^{46}$ para cumplir con el objetivo. La flexibilidad en el PMM, aparte de obedecer a las realidades geopolíticas al momento de negociar, no debe ser interpretada como una derogación de formulaciones precisas de política pública, sino como una herramienta para mejorar las capacidades de los estados para aplicar los principios rectores en sus acciones y políticas cotidianas ${ }^{47}$.

La medida en que tal ambigüedad constructiva es empleada en el PMM ha sido sujeta a algunas críticas, que a su vez reconocen que el PMM "no supone la existencia de un modelo universal de políticas migratorias, ni en el sentido de que exista un modelo teórico de validez global ni, menos aún, que se haya propuesto desde la ONU un modelo omnicomprensivo, único. Algo imposible, porque la gestión de la movilidad humana tiene supuestos históricos y contextuales propios no ya para cada región, sino para cada país" ${ }^{3}$. Consecuentemente, se ha dicho que el PMM no logra romper con el fenómeno de la "extranjerización" y que a su vez "No se combate suficientemente el condicionamiento etnocultural al reconocimiento y garantía de derechos, que fomenta xenofobia y racismo desde la falsa conexión lógica entre diferencia y desigualdad"49. Con mayor razón, la instrumentación del PMM deberá tener en mente los retos estructurales a la seguridad humana.

La relevancia del enfoque de seguridad humana al PMM es resaltado nuevamente al examinar los contenidos sobre poblaciones vulnerables. Mientras que el PMM establece que "Dentro de su jurisdicción soberana, los estados podrán distinguir entre el estatus migratorio regular e irregular" ${ }^{50}$, el proceso también reconoce que la condición migratoria irregular es, en efecto, una forma de vulnerabilidad ${ }^{51}$. La criminalización de mirantes irregulares, incluidos aquellos que han sido traficados, no es una estrategia efectiva. Adicionalmente, es violatoria del derecho internacional, toda vez que el Protocolo Contra el Tráfico llícito de Migrantes por Tierra, Mar y Aire establece que "Los migrantes no estarán sujetos a enjuiciamiento penal con arreglo al presente Protocolo [por el hecho de haber sido objeto de alguna de las conductas enunciadas]" 52 . Consecuentemente, el PMM utiliza la frase "independientemente de su condición migratoria" cuando se refiere a los derechos humanos, mismos que son universales y no pueden ser subyugados por actos de discriminación ${ }^{53}$.

La cuestión de irregularidad es atendida también en lo que corresponde al retorno,

46 La llamada "oración puente" entre cara compromiso y las acciones dice "Para cumplir este compromiso, recurriremos a las acciones siguientes". Fue sujeto de largas negociaciones a lo largo del proceso, ya que los Estados Miembros buscaban flexibilidad, al tiempo de atender la necesidad de acciones concretas y prácticas que podrían ser aplicadas a lo largo del documento.

47 LINOS, Katerina y PEGRAM, Tom, “The Language of Compromise in International Agreements”, en International Organization, vol. 20, Verano 2016.

${ }^{48}$ AIERBE, Peio, “Entrevista a Javier de Lucas, Derechos Humanos prioritarios” en Galde, 20 de junio de 2019: https://www.galde.eu/es/entrevistajavier-de-lucas/ [Consultado 3 diciembre 2019].

49 Ibídem

${ }^{50}$ ASAMBLEA GENERAL DE LAS NACIONES UNIDAS, A/RES/73//95 Pacto Mundial para la Migración Segura, Ordenada y Regular, op.cit., Párrafo I5c.

5) SANCHEZ, Gabriella, "Critical Perspectives on Clandestine Migration Facilitation:An Overview of Migrant Smuggling Research", en Journal on Migration and Human Security, vol. 5, $\mathrm{n}^{\circ}$. I, 2017

52 PROTOCOLO CONTRA EL TRAFICO ILICITO DE MIGRANTES POR TIERRA, MAR Y AIRE, QUE COMLPEMENTA LA CONVENCION DE LAS NACIONES UNIDAS CONTRA LA DELINCUENCIA ORGANIZADA TRANSNACIONAL,Articulo 5 parafraseado.

${ }^{53}$ GEST, Justin, KYSEL, lan M., y WONG, Tom K., "Protecting and Benchmarking Migrants' Rights: An Analysis of the Global Compact for Safe, Orderly and Regular Migration" en International Migration, vol. 57, $n^{\circ}$ 6, diciembre 2019, p. 63. 
reconociendo que es posible que algunos migrantes sencillamente no tienen derecho a permanecer en el territorio de un estado y pueden ser retornados al suyo, ya sea de manera voluntaria o no. En el Objetivo 2I del PMM, los Estados Miembros acuerdan que el retorno debe ser seguro y digno y se comprometen a "facilitar el regreso en condiciones de seguridad y dignidad y cooperar al respecto, y a garantizar el debido proceso, la evaluación individual y vías de recurso efectivas, respetando la prohibición de la expulsión colectiva y la devolución de los migrantes cuando corran un riesgo verdadero y previsible de morir o sufrir torturas y otros tratos o penas crueles, inhumanos o degradantes, u otros daños irreparables, de conformidad con nuestras obligaciones en virtud del derecho internacional de los derechos humanos" ${ }^{54}$. Algunos académicos han criticado al PMM por no citar el principio de non refoulement, mismo que podría haber otorgado a las personas migrantes mayores protecciones bajo el derecho internacional consuetudinario ${ }^{55}$. El tema fue discutido y tal principio fue específicamente mencionado en borradores de trabajo. Sin embargo, los Estados Miembros no pudieron acordar ampliación de cobertura a migrantes mediante un concepto exclusivamente asociado con refugiados en sus legislaciones nacionales. Como resultado, una versión menos abstracta - y por ello más práctica- del concepto fue incluida, detallando todas las fuentes relevantes del derecho internacional de los derechos humanos ${ }^{56}$.

En términos prácticos, el falso dilema de la ausencia del principio de non refoulement debería importarle poco a los migrantes en cuanto a la instrumentación del PMM.Al leer el texto entero, más allá del objetivo sobre retorno, existen provisiones para incorporar a migrantes que retornan al mercado laboral ${ }^{57}$, proveer información a lo largo del ciclo migratorio ${ }^{58}, y$ proporcionar identificación adecuada e identidad jurídica ${ }^{59}$. Aunado a ello, los conceptos de readmisión y reintegración sostenible enarbolan las responsabilidades compartidas de los estados y sus sociedades en esta etapa particular del ciclo migratorio. El objetivo sobre retorno busca asegurar que las vulnerabilidades desaparezcan, o bien, sean debidamente atendidas al retornar, "a fin de garantizar la seguridad, la dignidad y los derechos humanos de todos los migrantes que regresen" 60 .

La irregularidad como forma de vulnerabilidad fue planteada originalmente por la sociedad civil en la fase de consultas del proceso ${ }^{61}$, asentando así otra contribución de actores no estatales al PMM. La discusión dio lugar a intercambios sobre las causas de la irregularidad. Por un lado, la falta de vías legales fue presentada en las primeras conversaciones. Sin embargo, las causas subyacentes que llevan a grandes movimientos o a la migración irregular sistemática también

${ }^{54}$ ASAMBLEA GENERAL DE LAS NACIONES UNIDAS, A/RES/73//95 73//95. Pacto Mundial para la Migración Segura, Ordenada y Regular, op.cit., Párrafo 37.

${ }^{55}$ GEST, Justin, et.al. Protecting and Benchmarking Migrants' Rights... op. cit., p.5

${ }^{56}$ GUILD, Elspeth, BASARAN, Tugba y ALLINSON, Kathryn, From Zero to Hero? An analysis of the human rights protections within the Global Compact for Safe, Orderly and Regular Migration (GCM), en International Migration, vol. 57, $\mathrm{n}^{\circ}$ 6, diciembre 2019.

${ }^{57}$ ASAMBLEA GENERAL DE LAS NACIONES UNIDAS, A/RES/73//95 Pacto Mundial para la Migración Segura, Ordenada y Regular, op.cit., Párrafo 34.

58 Ibídem, Párrafos 19c y $28 \mathrm{e}$.

59 Ibid, Párrafo 20.

60 lbid, Párrafo $37 f$.

${ }^{61}$ SOOVA, Kadri, "Migration Status as Vulnerability Factor in Situations of Human Trafficking and Exploitation" en Platform for International Cooperation on Undocumented Migrants (PICUM), 3 I de octubre de 2012: https://picum.org/migration-status-as-vulnerability-factor-in-situationsof-human-trafficking-and-exploitation/ [Consultado 3 de agosto de 2019]. 
fueron discutidas. Una delegación incluso promovió un "Derecho a Permanecer" en el país de origen $^{62}$. Mientras que el "derecho a permanecer" no está jurídicamente creado en el PMM, el concepto de fondo - que las personas no deben verse obligadas a abandonar sus países de origen - fue bien recibido. En el Objetivo 2 del PMM, los estados se comprometen a "crear condiciones políticas, económicas, sociales y ambientales adecuadas para que las personas puedan vivir de manera pacífica, productiva y sostenible en su propio país y cumplir sus aspiraciones personales, evitando así que la desesperación y el deterioro del entorno las obliguen a recurrir a la migración irregular" 63 . Continúa haciendo referencia a la Agenda 2030 como el medio principal para asegurar que se generen tales condiciones. Consecuentemente, "el Pacto Mundial para la Migración impone responsabilidades compartidas como principio, ya que ninguna persona debería verse obligada a abandonar su país por una serie de factores adversos" ${ }^{64}$.

Sin embargo, lo anterior no siempre es posible. Practicantes de protección y asistencia humanitarias han llamado durante muchos años la atención a los vínculos entre cambio climático, desastres naturales y migración. No obstante, el tema seguía sin atención política. Mientras que algunas convenciones regionales consideran a personas desplazadas de manera transfronteriza por cambio climático como refugiados prima facie, la mayoría de los gobiernos no estaban preparados para tomar ese paso. Sin embargo, la discusión fue útil al visibilizar las necesidades de migrantes climáticos y los gobiernos tuvieron a bien considerar las mejores vías de acción. El PMM "es el primer acuerdo internacional en reconocer la migración climática, complementando las otras tres formas de migración regular: laboral, familiar y movilidad académica (Objetivo 5). El Pacto distingue entre dos tipos de migración climática: una se debe a 'la aparición repentina de desastres naturales', para la cual los estados deberán emplear criterios 'humanitarios de admisión, visas humanitarias, patrocinios privados, acceso a la educación para niños y permisos de trabajo temporales'. La otra obedece a 'desastres naturales de inicio lento, efectos adversos del cambio climático y degradación ambiental como la desertificación, degradación de tierras, sequias y el aumento de niveles del mar', para la cual los estados deberán considerar opciones de reasentamiento planeado y de visado'" 65 .

Otro tema importante en el PMM corresponde a los derechos laborales de los migrantes. Mientras que los migrantes representan únicamente el 3,4\% de la población global, generan casi el $9 \%$ del PIB del mundo66. Generalmente, los migrantes cruzan fronteras internacionales para trabajar. Sin embargo, las condiciones laborales precarias, regímenes explotadores de reclutamiento y políticas regulatorias inadecuadas dan lugar a abusos y, en algunos casos, trata de personas ${ }^{67}$. Mientras que se podría argumentar que la Convención sobre los Derechos de los Trabajadores Migratorios y sus Familiares debería de ser la referencia principal para atender

\footnotetext{
62 PERMANENT OBSERVER MISSION OFTHE HOLY SEE TO THE UNITED NATIONS, "Experts Call for Migration Talks to Include the Right to Remain in One's Country Of Origin", Statement by H.E. Archbishop Bernardito Auza, 22 de mayo 2017: https://holyseemission.org/contents// events/592c54513dea0.php [Consultado 2 de agosto de 2019].

${ }^{63}$ ASAMBLEA GENERAL DE LAS NACIONES UNIDAS, A/RES/73//95 73//95. Pacto Mundial para la Migración Segura, Ordenada y Regular, op. cit., Párrafo 18.

${ }^{64}$ GOMEZ CAMACHO, “Multilateralismo práctico", op. cit., p. 82.

${ }^{65}$ GUILD, et. al., From Zero to Hero? ...op. cit. pp. 9-I0.

${ }^{66}$ McKINSEY \& COMPANY, People on the Move: Global Migration's Impact and Opportunity, McKinsey Global Institute, Bruselas, 20I6, p. 8.

${ }^{67}$ ORGANIZACION INTERNACIONAL DEL TRABAJO,"Informe del Secretario General de las Naciones Unidas sobre el Pacto mundial para una migración segura, ordenada y regular:Aportaciones de la Organización Internacional del Trabajo", 2017: https://www.lo.org/wcmsp5/ groups/public/---ed_protect/---protrav/----migrant/documents/publication/wcms_59/492.pdf [Consultado I5 de julio de 2019].
} 
estas preocupaciones, su número extremadamente bajo de ratificaciones, aunado con la falta de apetito por instrumentos jurídicamente vinculantes obligó a los estados a ampliar su búsqueda de soluciones prácticas para mejorar la movilidad laboral ${ }^{68}$. Los derechos de los trabajadores migratorios están asentados integralmente a lo largo del PMM. El Objetivo 6 compromete a los estados a "facilitar la contratación equitativa y ética y salvaguardar las condiciones que garantizan el trabajo decente" ${ }^{69}$. Ello se traduce a una alineación con las convenciones relevantes de la Organización Internacional del Trabajo ${ }^{70}$, mejor regulación de reclutadores para prevenir servidumbre por deudas, explotación y trabajo forzado ${ }^{71}$, contratos escritos ${ }^{72}$, inspecciones laborales ${ }^{73}$ y revisiones legislativas para asegurar remedio efectivo cuando existan violaciones ${ }^{74}$. El PMM no busca crear un derecho a trabajar para las personas migrantes. Sin embargo, mejora la seguridad humana asegurando que aquellos que sí trabajan reciban las protecciones centrales del derecho internacional laboral.

Uno de los avances más importantes para trabajadores migratorios en el PMM se refiere a "desligar" las visas a un solo empleador. Mientras que muchos países condicionan la visa de trabajo a una empresa, las negociaciones atestiguaron evidencias de que esta práctica aumenta significativamente el riesgo de explotación. En lugar de poner fin a esta práctica (que en muchos casos sí da lugar a trabajo decente) el PMM invita a los estados a "Desarrollar y fortalecer la migración laboral y procesos de contratación equitativa y ética que permitan a los migrantes cambiar de empleador y modificar las condiciones o la duración de su estancia con mínimos trámites administrativos, promoviendo al mismo tiempo mayores oportunidades para el trabajo decente y el respeto del derecho internacional de los derechos humanos y del trabajo" ${ }^{75}$. Otro aspecto importante tiene que ver con migrantes que trabajan en la economía informal ${ }^{76}$, quienes habían estado totalmente ausentes de discusiones internacionales previas al PMM.

Otra contribución importante del PMM a la seguridad humana de los migrantes se refiere al bienestar de niñas y niños. La Convención de los Derechos del Niño es el tratado internacional de derechos humanos con el mayor número de ratificaciones, pero los treintaiun millones de niños viviendo fuera de sus países de origen ${ }^{77}$ merecían atención particular. Durante las negociaciones de la DNY, la cuestión de detención migratoria de menores fue muy controvertida.Algunos gobiernos citaron al Relator Especial sobre Tortura y Otras Formas de Trato o Castigo Cruel, Inhumano o Degradante, quien dijo que "[...] En el contexto de la detención administrativa por motivos de inmigración [...] la privación de libertad de niños a causa de la situación de migración de los

\footnotetext{
68 ARROCHA, Pablo, DE LA MORA, Fernando y DE LA FUENTE, Juan Ramón, "Migrantes y refugiados: las cosas por su nombre" en El Universal, 23 de julio de 2019: https://www.eluniversal.com.mx/articulo/pablo-arrocha-fernando-de-la-mora-y-juan-ramon-de-la-fuente/ nacion/migrantes-y-refugiados [Consultado 2 de agosto de 2019].

69 ASAMBLEA GENERAL DE LAS NACIONES UNIDAS A/RES/73// 95. Pacto Mundial para la Migración Segura, Ordenada y Regular, op.cit., Objetivo

70 Ibídem, Párrafo 22a.

71 Ibid, Párrafo $22 c$

72 Ibid, Párrafo 22d.

73 Ibid, Párrafo $22 f$.

74 Ibid, Párrafo $22 \mathrm{k}$.

75 Ibid, Párrafo 22g.

76 Ibid, Párrafos $22 \mathrm{i}$ y $22 \mathrm{j}$.

77 UNICEF, Desarraigados: Una Crisis Creciente para los Niños Refugiados y Migrantes, Fondo de las Naciones Unidas para la Infancia, Nueva York, 2016, p. 14.
} 
padres nunca respeta el interés superior del niño, supera el requisito de necesidad, se convierte en extremadamente desproporcionada y puede ser constitutiva de trato cruel, inhumano o degradante de los niños migrantes"78. Posteriormente, un Comentario General Conjunto del Comité de los Derechos del Niño y el Comité de los Derechos de los Trabajadores Migratorios y sus Familiares indicó que la detención migratoria de niños está "está en conflicto con el principio del interés superior del niño" 79 . Mientras tanto, otros gobiernos argumentaron que la detención temporal de niños era necesaria a fin de identificar posibles necesidades de protección y que, consecuentemente, tal práctica sí cumplía con el interés superior del niño.

Al final, el lenguaje en la Declaración de Nueva York aplica esencialmente el mismo estándar a niños que a la detención administrativa de adultos, lo cual representa un revés para los países que proponían poner fin a la práctica. Dice "reconociendo que, a los efectos de determinar la situación migratoria, la detención raras veces o nunca redunda en el interés superior del niño, la utilizaremos únicamente como medida de último recurso, en el entorno menos restrictivo, durante el período más breve posible, en condiciones que respeten los derechos humanos de cada niño y de manera que se tenga en cuenta como consideración primordial el interés superior del niño, y trabajaremos para poner fin a esa práctica" ${ }^{80}$. Gracias a un cabildeo concertado ${ }^{81}$, un proceso diplomático práctico y un análisis riguroso del derecho internacional aplicable, el PMM corrige este error, indicando que los Estados Miembros pueden "Proteger y respetar en todo momento los derechos y el interés superior del niño, independientemente del estatus migratorio, asegurando la disponibilidad y accesibilidad de diversas alternativas viables a la detención en contextos no privativos de libertad, en especial las modalidades de atención comunitaria, que garanticen el acceso a la educación y la atención sanitaria y respeten el derecho del menor a la vida familiar y la unidad de la familia, y procurando poner fin a la práctica de la detención de menores en el contexto de la migración internacional" ${ }^{2}$.

Aquí, además de establecer compromisos positivos en lugar de negativos, el precepto legal del interés superior del niño queda fuera de la acción específica, mientras que la frase "procurando poner fin" contrasta con "trabajaremos hacia poner fin" en lo que corresponde a detención de menores. Esto resalta cómo la dimensión de seguridad humana es aplicada desde una perspectiva práctica, en lugar de técnica. Mientras que el interés superior del niño está adecuadamente reflejado en el PMM a nivel de principio rector, un documento que no es jurídicamente vinculante cuya intención es tener implicaciones prácticas no requiere ser innecesariamente prescriptivo, siempre

78 MÉNDEZ, Juan, “Informe del Relator Especial sobre la tortura y otros tratos o penas crueles, inhumanos o degradantes, Juan E. Méndez", Consejo de Derechos Humanos de Naciones Unidas, A/HRC/28/68, Ginebra, 5 de marzo de 20I5: https://www.ohchr.org/EN/HRBodies/ HRC/RegularSessions/Session28/Documents/A_HRC_28_68_E.doc (Párrafo 80) [Consultado 3 de agosto de 2019].

79 COMITÉ DE PROTECCION DE LOS DERECHOS DETODOS LOSTRABAJADORES MIGRATORIOSY DE SUS FAMILIARES, “Observación general conjunta núm. 4 (20I7) del Comité de Protección de los Derechos de Todos los Trabajadores Migratorios y de sus Familiares y núm. 23 (2017) del Comité de los Derechos del Niño sobre las obligaciones de los Estados relativas a los derechos humanos de los niños en el contexto de la migración internacional en los países de origen, tránsito, destino y retorno", Naciones Unidas, CMW/C/GC/4-CRC/C/GC/23, Ginebra, 16 de noviembre de 2017: https://documents-dds-ny.un.org/doc/UNDOC/GEN/GI7/343/65/PDF/GI734365.pdf?OpenElement (Párrafo 10) [Consultado 3 de agosto de 2019].

80 ASAMBLEA GENERAL DE LAS NACIONES UNIDAS, A/RES/7 I// Declaración de Nueva York para los Refugiados y los Migrantes, op. cit., Párrafo 33.

81 INICIATIVA RELATIVA A LOS DERECHOS DEL NIÑO EN LOS PACTOS MUNDIALES “Nuestras Recomendaciones”, 20I7: https://www. childrenonthemove.org/our-recommendations/ [Consultado 29 de junio de 2019].

82 ASAMBLEA GENERAL DE LAS NACIONES UNIDAS, A/RES/73//95 Pacto Mundial para la Migración Segura, Ordenada y Regular, op cit., Párrafo $29 \mathrm{~h}$. 
y cuando la acción propuesta esté alienada con el derecho internacional existente. Finalmente, mientras que existen críticas en el sentido de que el PMM no logró una prohibición inmediata y total a la detención de menores ${ }^{83}$, el tema es también producto de las realidades políticas tomadas en cuenta en su momento ${ }^{84}$.

Al analizar con mayor profundidad la seguridad humana en el contexto del PMM, y siendo fiel a su naturaleza centrada en las personas, las percepciones de los propios migrantes sobre su seguridad humana también han sido tomadas en cuenta. El Relator Especial de la ONU sobre los Derechos Humanos de los Migrantes propuso que los "cortafuegos" entre fiscalización migratoria y otras autoridades fueran aceptados como buena práctica en el $\mathrm{PMM}^{85}$. Un número creciente de autoridades locales apoyan el concepto ${ }^{86}$, que se refiere prohibir que las autoridades migratorias interfieran en casos donde delitos están siendo reportados, o en donde servicios básicos a los que el migrante podría tener derecho han sido solicitados. Si un migrante siente que puede reportar delitos sin miedo a ser deportado, la seguridad de toda la comunidad mejora. Desde una perspectiva de seguridad humana, la lógica subyacente es que los cortafuegos pueden contribuir a la cohesión social y a la armonía comunitaria, removiendo el miedo a la deportación entre migrantes irregulares y empoderándoles a interactuar libremente con autoridades policiales y educativas, entre otras.

Mientras que las referencias explícitas a los cortafuegos fueron discutidas extensivamente en las negociaciones, la formulación aceptable fue la siguiente:"Asegurar que la cooperación entre los proveedores de servicios y las autoridades de inmigración no exacerbe la vulnerabilidad de los migrantes irregulares comprometiendo su acceso sin riesgo a los servicios básicos o vulnerando ilícitamente el derecho de la persona a la privacidad, la libertad y la seguridad física en los centros donde se presten servicios básicos ${ }^{87}$ ". El miedo a la deportación no debería prevenir que las personas migrantes accedan a servicios básicos, como es la educación para sus hijas e hijos. Sin embargo, ese temor sigue estando presente en muchas poblaciones migrantes. Una perspectiva de seguridad humana devela que es importante documentar y tomar en cuenta los aspectos tanto subjetivos como objetivos de las amenazas, ya que los datos sobre percepciones pueden ser claves para el desarrollo de políticas públicas ${ }^{88}$. De esta manera, la cooperación entre autoridades migratorias y sus contrapartes de otros sectores públicos no está categóricamente prohibida, pues ello podría también contravenir el principio pan gubernamental. Más bien, tales comunicaciones y cooperación no deben tener la finalidad de disminuir la seguridad humana de las personas migrantes ni de sus comunidades.

Otro tema relacionado a las amenazas subjetivas y percepciones corresponde a la tendencia

83 GOTTARDO y CYMENT,“The Global Compact for Migration: what could it mean for women and gender relations?”, op. cit., p.76.

${ }^{84}$ GUILD, et. al., From Zero to Hero? ..., op. cit., p.I0.

85 CREPEAU, Francois y HASTIE, Bethany, “The Case for 'Firewall' Protections for Irregular Migrants", en European Journal of Migration and Law, vol. I5, 2015.

${ }^{86}$ BRANDT, Jessica, "Implementing the Global Compact for Migration: Ideas for City Engagement”, en Brookings Institution Policy Briefs, octubre 2018: https://www.brookings.edu/wp-content/uploads/2018/I0/FP_201810I9_migration_compactl.pdf [Consultado 4 de junio de 20I9].

87 ASAMBLEA GENERAL DE LAS NACIONES UNIDAS, A/RES/73//95. Pacto Mundial para la Migración Segura, Ordenada y Regular, op. cit., Párrafo I5b.

${ }^{88}$ GOMEZ, Oscar y GASPER, Des, "Human Security: A Thematic Guidance Note for Regional and National Human Development Report Teams", Reporte de desarrollo humano de la oficina del Programa de las Naciones Unidas para el Desarrollo, 20I 3: http://hdr.undp.org/sites/default/ files/human_security_guidance_note_r-nhdrs.pdf [Consultado 4 de agosto de 2019]. 
preocupante de xenofobia que muchas veces es avivada por líderes políticos y los medios de comunicación, resultando en comunidades aterrorizadas. El auge del discurso de odio ha tenido consecuencias muy tangibles. De forma más reciente, el ataque terrorista contra hispanos y mexicanos en El Paso, Texas, ha sido ligado a retórica política de exclusión antinmigrante ${ }^{89}$. En el ataque terrorista de Christchurch, Nueva Zelandia, el perpetrador incluso citó al PMM como motivación para su acto de violencia ${ }^{90}$. El Secretario General de la ONU,António Guterres, lanzó en mayo de 2019 la Estrategia y Plan de Acción de la ONU sobre Discurso de Odio91.

El PMM busca atender las percepciones y los prejuicios hacia los migrantes de la misma manera que caracterizó el proceso diplomático. El Objetivo 17 del PMM establece "Nos comprometemos a eliminar todas las formas de discriminación y a condenar y combatir las expresiones, los actos y las manifestaciones de racismo, discriminación racial, violencia, xenofobia y formas conexas de intolerancia contra todos los migrantes, de conformidad con el derecho internacional de los derechos humanos. Nos comprometemos además a promover, en colaboración con todos los sectores de la sociedad, un discurso público abierto y con base empírica sobre la migración y los migrantes que genere una percepción más realista, humana y constructiva a este respecto. Nos comprometemos también a proteger la libertad de expresión de conformidad con el derecho internacional, reconociendo que el debate abierto y libre contribuye a la comprensión cabal de todos los aspectos de la migración" 92.

Este texto retoma la Convención Internacional para la Eliminación de Todas las Formas de Discriminación Racial. Sin embargo, la crítica hacia el PMM se ha enfocado en una sección particular, el Objetivo 17(c):"Promover un periodismo independiente, objetivo y de calidad en los medios de comunicación, incluida la información publicada en Internet, por ejemplo, sensibilizando y educando a los profesionales de los medios informativos sobre las cuestiones y la terminología relacionadas con la migración, invirtiendo en normas y publicidad sobre la ética del periodismo, y dejando de asignar fondos públicos o apoyo material a los medios de difusión que promuevan sistemáticamente la intolerancia, la xenofobia, el racismo y otras formas de discriminación contra los migrantes, pero respetando plenamente la libertad de los medios de comunicación" ${ }^{93}$. El hecho de que muchos gobiernos, a veces de manera inadvertida, están financiando plataformas que alientan el discurso de odio fue expuesto en las tres fases de elaboración del PMM ${ }^{94}$. Sin embargo, los activistas de redes sociales que han liderado los ataques contra el PMM señalan falsamente que la crítica a la migración estaría de alguna manera fuera de la ley o prohibida ante la propuesta de sentido común acordada por los gobiernos. Esta aseveración ha sido consistentemente desmentida,

${ }^{89}$ GRAHAM, David, “Mexico pushes US to designate El Paso shooting an act of terrorism” en Reuters, 14 de agosto de 2019: https://www. reuters.com/article/us-texas-shooting-mexico/mexico-pushes-us-to-designate-el-paso-shooting-an-act-of-terrorism-idUSKCNIV4IU4 [Consultado 15 de agosto de 2019].

${ }^{90}$ ENCABO, Louie, "How UN Global Compact hysteria is driving far-right extremism in New Zealand" en The Defiant, 19 de marzo de 2019: https://thedefiant.net/how-un-global-compact-hysteria-is-driving-far-right-extremism-in-new-zealand/ [Consultado I5 de agosto de 2019].

91 Naciones Unidas, “Estrategia y el Plan de Acción contra el llamado discurso del odio de las Naciones Unidas.", Nueva York, mayo 2019: https:// www.un.org/en/genocideprevention/documents/UN\%20Strategy\%20and\%20Plan\%20of\%20Action\%20on\%20Hate\%20Speech\%20I8\%20 Junio\%20SYNOPSIS.pdf [Consultado I5 de agosto de 2019].

92 ASAMBLEA GENERAL DE LAS NACIONES UNIDAS, A/RES/73//95. Pacto Mundial para la Migración Segura, Ordenada y Regular, op. cit., Párrafo 33.

${ }^{93}$ Ibídem, Párrafo 33c.

${ }^{94}$ STOP FUNDING HATE, "Five reasons why the UN Global Compact for Migration is good news for anti-hate campaigners", Stop Funding Hate, Londres, 23 de diciembre de 2018: https://stopfundinghate.info/2018/I2/23/five-reasons-why-the-un-global-compact-for-migration-isgood-news-for-anti-hate-campaigners/ [Consultado 10 de agosto de 2019]. 
incluida de manera prominente por la ONG de libertad de expresión Artículo 1995

Si bien, se respeta la libertad de expresión y se presenta un llamado a periodismo y mercadotecnia éticos, sigue pendiente la incógnita respecto a las percepciones públicas sobre las personas migrantes y la inhabilidad de los datos en alterar el sentir público. Estudios recientes demuestran que los números, hechos y datos duros tienden a impactar poco o nada entre aquellos comprometidos a un sentimiento antiinmigrante ${ }^{96}$. Considerando las implicaciones graves que el discurso de odio puede tener sobre la cohesión social, por no hablar de las consecuencias políticas de los nacionalismos excluyentes, la formulación de soluciones creativas a futuro caerá en manos de alianzas innovadoras. Muchas de las soluciones podrán guiarse por las disciplinas de las psicologías sociales y aplicadas ${ }^{97}$.

EI PMM adopta un enfoque integral que considera los intereses de estados, migrantes y comunidades. Esencialmente, es la naturaleza práctica del documento la que puede tener un impacto en el terreno, produciendo resultados en materia de seguridad humana. El hecho de que el "espectro de compromisos reflejados en el PMM, si es que son implementados a nivel global o regional, mejorarían sustantivamente las vidas de millones de migrantes en los años por venir" ${ }^{98}$ se debe, en buena medida, a que éstos están firmemente anclados en el derecho internacional de los derechos humanos existente. El PMM no impone nuevas obligaciones a los estados, pero presenta un marco cooperativo que facilita el respeto a los derechos humanos al poner cuestiones prácticas sobre su cumplimiento en un solo documento integral.

\section{Conclusión}

Este análisis resalta algunos aspectos de un nuevo tipo de acuerdo internacional, propiamente un Pacto Mundial. Es jurídicamente no vinculante, políticamente influyente, intrínsecamente práctico y requiere de alianzas entre múltiples partes interesadas para ser aplicado. A lo largo de su desarrollo, el enfoque de seguridad humana estuvo presente, ya sea de manera implícita o explícita. Es notable que la reunión de balance en Puerto Vallarta haya obligado a los Estados Miembros a analizar sus políticas y posiciones a través de múltiples lentes correspondientes a niveles de análisis distintos: desde el individual hasta el global. Para la ONU, se trata de una innovación rezagada que tuvo efectos profundos sobre las posiciones gubernamentales. Más allá del cliché, este proceso diplomático generó verdaderos entendimientos a través del diálogo. El hecho de que un órgano tan complejo y diverso como la Asamblea General de la ONU haya podido lograr esto - mientras muchos parlamentos nacionales han sido incapaces de sobrepasar los enfrentamientos en torno a la migración - es un hito. Que todo haya sucedido en momento de división extrema es un testamento al valor perdurable del multilateralismo práctico.

\footnotetext{
95 ARTICLE 19, "Global Compact for Migration positive for ensuring free expression, access to information, and inclusive public debate", Article 19, 10 de diciembre 2018: https:/www.articlel9.org/resources/global-compact-for-migration-positive-for-ensuring-free-expression-accessto-information-and-inclusive-public-debate/ [Consultado 15 de agosto de 2019].

96 DESMARES, Camille, Addressing Xenophobia: Representations of Migration and the Role of the Media, United Nations University (Institute on Globalization, Culture and Mobility), Barcelona, 2017

97 AMERICAN PSYCHOLOGICAL ASSOCIATION, Crossroads: The Psychology of Immigration in the New Century, American Psychological Association Presidential Task Force on Immigration, Washington, D.C., 2012.

98 GEST, Justin, et.al. Protecting and Benchmarking Migrants' Rights... op. cit. p. 10.
} 
Las tensiones entre soberanía nacional y los derechos de los migrantes representan otra manifestación de los debates bien conocidos sobre el estado vs. el individuo. La capacidad de los estados a plantear sus propias políticas migratorias está plenamente respetada por el PMM. Pero la realidad dicta que su éxito al intentar hacer que la migración sea segura, ordenada y regular debe necesariamente acompañarse de una sana dosis de cooperación internacional. Sencillamente, la mejor forma de ejercer la soberanía nacional en materia migratoria es a través de la cooperación con otros estados soberanos ${ }^{99}$. El proceso diplomático permitió que gobiernos y organizaciones migrantes se reunieran a compartir realidades, preocupaciones e intereses de una manera estructurada y con un propósito común.

Al negociar sobre la base de datos y evidencia, los intereses legítimos que eran aparentemente opuestos salieron a la luz.Algunas de estas áreas incluyeron la atención a las causas de la migración, los derechos de los trabajadores migratorios, los procedimientos de retorno, la xenofobia, la gestión integrada de fronteras y detención de menores, entre otras. Fue necesario sobrepasar paradigmas anquilosados de "nosotros vs. ellos" para llegar a un acuerdo. Ello se logró gracias al reconocimiento de que la categorización de países como "origen, tránsito o destino" era de poca utilidad. Con ello, entender el fenómeno migratorio desde una sola perspectiva era sencillamente imposible.

La perspectiva de seguridad humana contribuyó a encontrar soluciones pragmáticas a temas contenciosos. Mientras que algunos gobiernos asumieron el papel de abogacía a favor de sus connacionales en el extranjero, otros abogaban por sus ciudadanos en comunidades receptoras de migrantes. Las discusiones sobre provisión de servicios, cortafuegos y procedimientos migratorios encontraron soluciones en buena medida porque todas las delegaciones fueron capaces de "visualizar" los resultados negociados. Hoy, cualquier persona debe poder leer el PMM y dibujar un retrato que describe cualquiera de sus acciones. Al final, los protagonistas son los migrantes, los gobiernos y las comunidades. El grado en que estos tres actores puedan ver sus intereses reflejados en el resultado negociado depende directamente del enfoque prestado a necesidades y posibilidades individuales, llevando la discusión más allá de conceptos abstractos.

La contribución del paradigma de seguridad humana al PMM es evidente por la atención dedicada a vulnerabilidades.Aquellas personas desplazadas por la aparición de desastres naturales repentinos o de inicio lento, migrantes extraviados y aquellos sujetos a diversas formas de explotación están contemplados en el texto. De manera importante, se considera la irregularidad migratoria como forma de vulnerabilidad que habrá de evitarse. Múltiples herramientas están disponibles para los Estados Miembros en este sentido. Mientras que la mayoría de la migración en el mundo se realiza de manera segura, ordenada y regular, visibilizar las externalidades complejas que conlleva en el contexto migratorio obligó a los gobiernos a atender otros problemas apremiantes relacionados, como la trata de personas y el tráfico de migrantes. Las amenazas objetivas y subjetivas a la seguridad humana que fueron identificadas en las discusiones previas son respaldan las soluciones identificadas. Por ejemplo, el objetivo entero dedicado a la información puntual y confiable brindará mayor certeza y predictibilidad tanto a los migrantes como a los estados.

99 ARROCHA, Pablo, DE LA MORA, Fernando, et. al., "Migración: la perspectiva multilateral”, op. cit., 
El PMM no disfruta de un respaldo unánime entre todos los Estados Miembros de la ONU. Sin embargo, sí cuenta con un apoyo preponderante de una supermayoría de los gobiernos. La minoría de los que se oponen al PMM han sido incapaces de articular o proponer un marco alternativo que haría a la migración segura, ordenada y regular. Incluso, la ONU ha logrado regresar al consenso en torno a negociaciones con referencias al PMM ${ }^{100}$. Mientras tanto, millones de migrantes continúan aportando a los países de origen y destino. Las sociedades tienen mucho que ganar del capital humano que representan. En los próximos años, la ONU seguirá siendo prominente, operando el Fondo Fiduciario para la Migración Segura, Ordenada y Regular y albergando el primer Foro de Examen sobre Migración Internacional en 2022, mismo que valorará el progreso en la instrumentación del PMM. La seguridad humana no carece de detractores, pero ha demostrado una vez más que los avances significativos en las relaciones internacionales no pueden darse el lujo de ignorar el impacto de las políticas públicas sobre los individuos.

Viendo a futuro, aquellos que facilitan procesos diplomáticos harían bien en involucrar desde las etapas iniciales de su planeación a la sociedad civil. La proliferación de actores relevantes en virtualmente cualquier tema global puede hacer que las cosas parezcan desordenadas, pero ese desorden puede traducirse en sofisticación. La seguridad humana permite a los participantes visualizar los resultados que dan lugar a acciones prácticas en el terreno. Sin embargo, resulta indispensable que todos los practicantes y estudiosos estén agudamente conscientes de las resistencias que perduran en negociaciones explícitas sobre el paradigma en entornos multilaterales. Una aproximación balanceada y pragmática a la diplomacia de la seguridad humana sí puede brindar resultados significativos para atender los retos apremiantes por delante.

\section{Bibliografía}

AIERBE, Peio, "Entrevista a Javier de Lucas, Derechos Humanos prioritarios" en Galde, 20 de junio de 2019: https:// www.galde.eu/es/entrevista-javier-de-lucas/ [Consultado 3 de diciembre de 2019].

AMERICAN JOURNAL OF INTERNATIONAL LAW, “Trump Administration Ends Participation en Global Compact on Migration, Citing Concerns Regarding U.S. Sovereignty" en American Journal of International Law, vol. I I 2, $N^{\circ} 2,2018$, pp. 3III-3I3.

AMERICAN PSYCHOLOGICALASSOCIATION, Crossroads:The Psychology of Immigration in the New Century, American Psychological Association Presidential Task Force on Immigration, Washington, D.C., 2012.

ARANGO, Joaquín, MAHÍA, Ramón, MOYA, David y SÁNCHEZ-MONTIJANO, Elena, Inmigración y Asilo en el centro de la arena politica, Barcelona Centre for International Affairs, Barcelona, 2018.

ARROCHA, Pablo, DE LA MORA, Fernando y DE LA FUENTE, Juan Ramón "Migración: la perspectiva multilateral" en El Universal, 28 de julio de 2019: https://www.eluniversal.com.mx/nacion/sociedad/migracion-la-perspectivamultilateral [Consultado 29 de julio de 2019].

ARROCHA, Pablo, DE LA MORA, Fernando y DE LA FUENTE, Juan Ramón, “Migrantes y refugiados: las cosas por su nombre" en El Universal, 23 de julio de 2019: https://www.eluniversal.com.mx/articulo/pablo-arrochafernando-de-la-mora-y-juan-ramon-de-la-fuente/nacion/migrantes-y-refugiados [Consultado el 2 de agosto de 2019].

ARTICLE 19,"Global Compact for Migration positive for ensuring free expression, access to information, and inclusive public debate", Article 19, 10 de diciembre de 2018: https://www.article 19.org/resources/global-compactfor-migration-positive-for-ensuring-free-expression-access-to-information-and-inclusive-public-debate/ [Consultado el de 15 de agosto de 2019].

ASAMBLEA GENERAL DE LAS NACIONES UNIDAS, A/RES/60/I Documento Resultado de la Cumbre Mundial 2005, Nueva York, 24 de octubre 2005.

ASAMBLEA GENERAL DE LAS NACIONES UNIDAS, A/RES/66/290 Seguimiento al párrafo 143 sobre seguridad

\footnotetext{
${ }^{100}$ EL UNIVERSAL, “Por consenso, ONU adopta resolución mexicana para protección de migrantes” en El Universal, I5 de noviembre de 2019 : https://www.eluniversal.com.mx/nacion/por-consenso-onu-adopta-resolucion-mexicana-para-proteccion-de-migrantes [Consultado 2 de diciembre de 2019].
} 
humana del Documento Resultado de la Cumbre Mundial de 2005, Nueva York, 25 de octubre de 2012.

ASAMBLEA GENERAL DE LAS NACIONES UNIDAS, A/RES/70/I Transformando nuestro mundio: la Agenda 2030 para el Desarrollo Sostenible, Nueva York, 21 de octubre de 2015.

ASAMBLEA GENERAL DE LAS NACIONES UNIDAS, A/RES/7I/I Declaración de Nueva York para Refugiados y Migrantes, Nueva York, 3 de octubre de 2016.

ASAMBLEA GENERAL DE LAS NACIONES UNIDAS, A/RES/7//280 Modalidades para las negociaciones intergubernamentales del pacto mundial para la migración segura, ordenada y regular, Nueva York, 17 de abril de 2017.

ASAMBLEA GENERAL DE LAS NACIONES UNIDAS, A/RES/73//95 Pacto Mundial para la Migración Segura, Ordenada y Regular, Nueva York, II de enero de 2019.

BILGIC, Ali, A Human Security Perspective on Migration: A Compass for the Perfect Storm, International Institute of Social Studies, La Haya, 12 de abril de 2018.

BOLTON, Matthew, The Nuclear Weapons Ban and Human Security for All, Freidrich Ebert Stiftung, New York, 20I7: http://library.fes.de/pdf-files/iez/I3435.pdf [Consultado el I9 de junio de 2019].

BOULBY, Marion and CHRISTIE, Kenneth (eds), Migration, Refugees and Human Security in the Mediterranean and MENA, Palgrave McMillan, Suiza, 2018, pp. I-25I.

BRANDT, Jessica,"Implementing the Global Compact for Migration:Ideas for City Engagement”, en Brookings Institution Policy Briefs, octubre 2018: https://www.brookings.edu/wp-content/uploads/2018/I0/FP_20181019_ migration_compactl.pdf [Consultado el 4 de junio de 2019].

CARLING, Jørgen, “A landmark in the landscape of migration studies”, en Ethnic and Racial Studies, vol. 38, $\mathrm{n}^{\circ}$ I3, 20I5, Pp. 2373-2376.

COLOMÉ MENÉNDEZ, Desirée, "Fronteras movedizas", en Opiniones Oportunas del Consejo Mexicano de Asuntos Intenacionales, 26 de julio de 2019: http://revistafal.com/fronteras-movedizas/ [Consultado el 27 de julio de 2019].

CREPEAU, Francois y HASTIE, Bethany, “The Case for 'Firewall' Protections for Irregular Migrants”, en European Journal of Migration and Law, vol. 17, 2015.

DE CHICKERA, Amal y WHITEMAN, Joanna, "Discrimination and the human security of stateless people" en Forced Migration Review, ${ }^{\circ}$ 46, 2014, 56-69.

DE LA MORA SALCEDO, Fernando y GÓMEZ CAMACHO, Juan José,“Negociación de 360 grados: el Pacto Mundial para la Migración Segura, Ordenada y Regular” en Otros Diálogos, n. 7, 28 de marzo de 2019.

DE LA MORA SALCEDO, Fernando y GÓMEZ CAMACHO, Juan José, México ante el Pacto Mundial para la Migración, Centro de Investigación y Docencia Económicas (CIDE), Ciudad de México, mayo de 2019.

DESMARES, Camille, Addressing Xenophobia: Representations of Migration and the Role of the Media, United Nations University Institute on Globalization, Culture and Mobility, Barcelona, 2017.

DOMICELJ, Tamara y GOTTARDO, Carolina, "Implementing the Global Compacts: the importance of a whole-ofsociety approach" en Forced Migration Review, n 60, 2019, pp. 79-82.

DONATO, Katharine M. y SISK, Blake, "Children's Migration to the United States from Mexico and Central America: Evidence from the Mexican and Latin American Migration Projects" en Journal of Migration and Human Security, vol. 3, $\mathrm{n}^{\circ}$ I, 20I5, pp. 58-79.

ENCABO, Louie, "How UN Global Compact hysteria is driving far-right extremism in New Zealand” en The Defiant, 19 de marzo de 2019: https://thedefiant.net/how-un-global-compact-hysteria-is-driving-far-right-extremismin-new-zealand/ [Consultado el I5 de agosto de 2019].

EL UNIVERSAL, "Por consenso, ONU adopta resolución mexicana para protección de migrantes" en El Universal, I5 de noviembre de 2019: https://www.eluniversal.com.mx/nacion/por-consenso-onu-adopta-resolucionmexicana-para-proteccion-de-migrantes [Consultado 2 de diciembre de 2019]

FERREIRA, Susana, Human Security and Migration in Europe's Southern Borders. Palgrave McMillan, Cham, 20I 9, pp. I-205.

GENINA,Víctor, "Proposals for the Negotiation Process on the United Nations Global Compact for Migration" en Journal of Migration and Human Security, vol. 5, $n^{\circ}$ 3, 2017, pp. 682-693.

GEST, Justin, KYSEL, lan M., y WONG, Tom K., "Protecting and Benchmarking Migrants' Rights: An Analysis of the Global Compact for Safe, Orderly and Regular Migration" en International Migration, vol. 57, $n^{\circ}$ 6, diciembre 2019, pp. 60-79.

GLADWELL, Catherine, "Accessing and thriving in education in the UK” en Forced Migration Review, $\mathrm{n}^{\circ}$ 60, 2019, pp. 43-46.

GÓMEZ CAMACHO, Juan José, “Multilateralismo práctico” en Foreign Affairs Latinoamérica, vol. I9, n. I, enero-marzo 2019.

GÓMEZ, Oscar and GASPER, Des, "Human Security: A Thematic Guidance Note for Regional and National Human Development Report Teams”, United Nations Development Programme Human Development Report Office, 20 I 3 : http://hdr.undp.org/sites/default/files/human_security_guidance_note_r-nhdrs.pdf [Consultado 4 de agosto de 2019].

GOTTARDO, Carolina, y CYMENT,Paola, "The Global Compact for Migration: what could it mean for women and gender relations?" en Gender \& Development, vol. 27, n I, 2019, pp. 67-83.

GRAHAM, David, "Mexico pushes US to designate El Paso shooting an act of terrorism" en Reuters, I4 de agosto de 2019: https://www.reuters.com/article/us-texas-shooting-mexico/mexico-pushes-us-to-designate-el-paso- 
shooting-an-act-of-terrorism-idUSKCNIV4IU4 [Consultado el I5 de agosto de 2019].

GUILD, Elspeth, BASARAN, Tugba y ALLINSON, Kathryn, From Zero to Hero? An analysis of the human rights protections within the Global Compact for Safe, Orderly and Regular Migration (GCM), en International Migration, vol. 57, $\mathrm{n}^{\circ} 6$, diciembre 2019, pp. 43-59.

HAMAID, Muneer, “Foreign fighters: a five eyes border management perspective” en Journal of Policing, Intelligence and Counter Terrorism, vol. I2, n`I, 2017, pp. 47-65.

IAKOVIDIS, lakovos, GALARIOTIS, loannis and GIANNIOU, Maria, "The formation of the EU negotiating strategy at the UN: the case of human rights" en Cambridge Review of International Affairs, vol. 31 , n 5, 20I 8, pp. 437-459.

INDEPENDENT INTERNATIONAL COMMISSION ON KOSOVO, The Kosovo Report: Conflict, International Response, Lessons Learned, Oxford University Press, Oxford, 2000.

INITIATIVE FOR CHILD RIGHTS IN THE GLOBAL COMPACTS, “Our recommendations", 20I7: https://www. childrenonthemove.org/our-recommendations/ [Consultado el 29 de junio de 2019].

INTERNATIONAL LABOUR ORGANIZATION, "Inputs of the International Labour Organization to the UN Secretary-General's report on the Global Compact for Safe, Orderly and Regular Migration" 2017: https:/www.ilo.org/wcmsp5/groups/public/---ed_protect/---protrav/---migrant/documents/publication/ wcms_59|492.pdf [Consultado el I5 de julio de 2019].

INTERNATIONAL ORGANIZATION FOR MIGRATION, “IOM Becomes a Related Organization to the UN", IOM Press Release, 25 Julio 2016: https://www.iom.int/news/iom-becomes-related-organization-un [Consultado el 10 de junio de 2019].

KING, Russell,"Migration comes of age” en Ethnic and Racial Studies, vol. 38, n I3, 20I5, pp. 2366-2372.

KOSER, Khalid, "Chapter 12: Migration and Security: Exploding the Myths and Understanding the Realities" en GRAEME, Hugo, JALAL ABBASI-SHAVAZI, Mohammad, y KRACY, Ellen, (eds.) Demography of Refugee and Forced Migration, Springer International Publishing, Suiza, 2018, pp. I-309.

KOSER, Khalid, Irregular migration, state security and human security, Global Commission on International Migration, Londres, septiembre 2005.

KYTOMAKI, Elli, The Arms Trade Treaty and Human Security: Cross-cutting Benefits of Accession and Implementation, Chatham House, Londres, 20I5: https:/www.chathamhouse.org/sites/default/files/field/field_ document/20I50220ATTKytomaki.pdf [Consultado el 20 de junio de 2019].

LAVENEX, Sandra, "Regional migration governance - building block of global initiatives?" en Journal of Ethnic and Migration Studies, vol. 45, n 8, 2019, pp. I275-I 293.

LINOS, Katerina y PEGRAM, Tom, "The Language of Compromise in International Agreements" en International Organization, vol. 70, $\mathrm{n}^{\circ}$ 3, $2016, \mathrm{pp}$. 587-621.

MACFARLANE, S. Neil and FOON KHONG, Yuen, Human Security and the UN: A Critical History, Indiana University Press, Bloomington, 2006.

McKINSEY \& COMPANY, People on the Move: Global Migration's Impact and Opportunity, McKinsey Global Institute, Bruselas, 2016.

MCRAE, Rob, International Relations and the New Diplomacy en Human Security and the New Diplomacy MCRAE, Rob y HUBERT, Ron (eds), McGill-Queen's University Press, Montreal, 200 I.

MENDEZ, Juan, "Report of the Special Rapporteur on torture and other cruel, inhuman or degrading treatment or punishment, Juan E. Méndez", United Nations Human Rights Council, A/HRC/28/68, Ginebra, 5 de marzo de 2015: https:/www.ohchr.org/EN/HRBodies/HRC/RegularSessions/Session28/Documents/A HRC 2868 E.doc [Consultado el 3 de agosto de 2019].

MISIÓN OBSERVĀDŌRA PERMANENTE DE LA SANTA SEDE ANTE LAS NACIONES UNIDAS, "Experts Call for Migration Talks to Include the Right to Remain in One's Country Of Origin", Statement by H.E. Archbishop Bernardito Auza, 22 de mayo de 2017: https://holyseemission.org/contents//events/592c545I3dea0.php [Consultado el 2 de agosto de 2019].

NACIONES UNIDAS, "Agenda of the Preparatory (stocktaking) meeting of the Intergovernmental Conference to adopt a Global Compact for Safe, Orderly and Regular Migration", 4 de diciembre de 2017: https:// refugeesmigrants.un.org/sites/default/files/pv_agenda_03122017_rev.pdf, [Consultado el 14 de junio de 2019].

NACIONES UNIDAS, “Regional Consultations for the Global Compact for Migration” 2017: https://refugeesmigrants. un.org/regional-consultations, [Consultado el 2 de agosto de 2019].

NACIONES UNIDAS, “United Nations Strategy and Plan of Action on Hate Speech”, New York, mayo 2019: https:// www.un.org/en/genocideprevention/documents/UN\%20Strategy\%20and\%20Plan\%20of\%20Action\%20 on\%20Hate\%20Speech\%2018\%20]unio\%20SYNOPSIS.pdf [Consultado el I5 de agosto de 2019].

PETRASEK, David, “New powers, new approaches? Human Rights Diplomacy in the 2 I st Century” en International Journal on Human Rights, $n^{\circ}$ 19, 2013, pp. 6-I5.

PINYOL-JIMENEZ, Gemma "Otro paradigma migratorio: La percepción del fenómeno como una amenaza ha privado de un debate que es necesario" en El País, 5 de julio de 2020: https://elpais.com/elpais/2018/07/05/ opinion/I5308I4645_466534.html [Consultado 5 de diciembre de 2019].

PIPER, Nicola, "Democratising Migration from the Bottom Up:The Rise of the Global Migrant Rights Movement" en Globalizations, vol. I2, n 5, 20I5, pp. 788-802.

PIPER, Nicola, “Migration and the SDGs” en Global Social Policy, vol. I7, n 2, 20I 7, pp. 23 I-238. 
POTTLER, Maximilian, “Humanitarian border management” en Forced Migration Review, № 45, 20I4, pp. 46-47.

PROGRAMA DE DESARROLLO DE LAS NACIONES UNIDAS, “Putting Human Rights Up Front”, New York, 7 de agosto de 2018: https://stories.undp.org/putting-human-rights-up-front [Consultado el 19 de junio de 2019].

PROGRAMA DE DESARROLLO DE LAS NACIONES UNIDAS, 1994 Human Development Report, United Nations, New York, 1994

PURKAYASTHA, Bandana, “Migration, migrants, and human security” en Current Sociology Monograph, vol. 66, $\mathrm{n}^{\circ} 2$, 2018, pp. |67-19|.

REED, Holly, "Forced Migration and Undocumented Migration and Development", United Nations Department of Economic and Social Affairs, New York, 2 de noviembre de 2018.

ROCK, Allan, "The Human Security Network, Fifteen Years On” en Center for International Policy Studies, 21 de mayo de 2013: https://www.cips-cepi.ca/2013/05/2I/the-human-security-network-fifteen-years-on/ [Consultado el 30 de julio de 2019].

ROSENOW-WILLIAMS, Kerstin and BEHMER, Katharina, “A Gendered Human Security Perspective in Humanitarian Action in IDP and Refugee Protection", en Refugee Survey Quarterly, n³4, 2015, pp. I-23.

SAN JOSE, Benjamin, "Achieving human security for migrants: the limits of state policies and migration development initiatives" en Bandung Journal of Global South, 20 I5, pp. I-3.

SANCHEZ, Gabriella, "Critical Perspectives on Clandestine Migration Facilitation:An Overview of Migrant Smuggling Research" en Journal of Migration and Human Security, vol. 5, $n^{\circ}$ I, 20I7, pp. 9-27.

SERÓN, Gema, "El Pacto Mundial sobre Migración: algunas reflexiones tras la cumbre en Davos" en Memorando OPEX No. 24//2019, I5 de marzo de 2019: https://www.fundacionalternativas.org/public/storage/opex documentos_archivos/bbaa6d840e43 I0b6d840I0b062272d85.pdf, p. 3 [Consultado el I0 de junio de 20I9].

SKELDON, Ronald, "What's in a title? The fifth edition of The Age of Migration" in Ethnic and Racial Studies, vol. 38, $\mathrm{n}^{\circ}$ I3, 20I5, pp. 2356-236I.

SOOVA, Kadri, "Migration Status as Vulnerability Factor in Situations of Human Trafficking and Exploitation" in Platform for International Cooperation on Undocumented Migrants (PICUM), 31 de octubre de 2012: https://picum.org/ migration-status-as-vulnerability-factor-in-situations-of-human-trafficking-and-exploitation/ [Consultado el 3 de agosto de 2019].

STOP FUNDING HATE, "Five reasons why the UN Global Compact for Migration is good news for anti-hate campaigners", Stop Funding Hate, London, 23 de diciembre de 20 I8: https://stopfundinghate.info/20 I8//2/23/ five-reasons-why-the-un-global-compact-for-migration-is-good-news-for-anti-hate-campaigners/ [Consultado el 10 de agosto de 2019].

UNICEF, Uprooted:The Growing Crisis for Refugee and Migrant Children, United Nations Children's Fund, New York, 2016.

UNIDAD DE SEGURIDAD HUMANA DE LAS NACIONES UNIDAS, “Human Security Trust Fund”, 2019: https:// www.un.org/humansecurity/trustfund/, [Consultado el 27 de mayo de 2019].

ÜNVER, Can, "Migration in International Relations: Towards a Rights-Based Approach with Global Compact?" en Perceptions, vol. 22, $n^{\circ}$ 4, 2017, pp. 85-102.

WEHRENFENNI, Daniel, “Multi-Track Diplomacy and Human Security” en Journal of Human Security, vol. 7, 2008, pp. 80-89. 


\section{RELACIONES INTERNACIONALES}

Revista académica cuatrimestral de publicación electrónica Grupo de Estudios de Relaciones Internacionales (GERI)

Universidad Autónoma de Madrid, España

https://revistas.uam.es/relacionesinternacionales

ISSN 1699 - 3950

f facebook.com/RelacionesInternacionales

3. twitter.com/RRInternacional

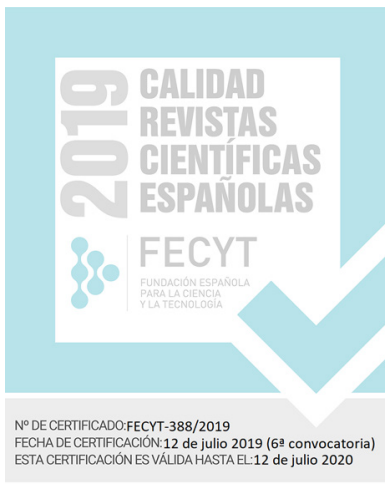

